\title{
The oxytocin receptor gene, an integral piece of the evolution of Canis familaris from Canis Iupus
}

\author{
Jessica Lee Oliva ${ }^{1}$, Yen T Wong ${ }^{2}$, Jean-Loup Rault ${ }^{3}$, Belinda Appleton ${ }^{2}$, Alan Lill ${ }^{4}$
}

Abstract

Previous research in canids has revealed both group (dog versus wolf) and individual differences in object choice task (OCT) performance. These differences might be explained by variation in the oxytocin receptor (OXTR) gene, as intranasally administered oxytocin has recently been shown to improve performance on this task by domestic dogs. This study looked at microsatellites at various distances from the OXTR gene to determine whether there was an association between this gene and: i) species (dog/wolf) and ii) good versus bad OCT performers. Ten primer sets were designed to amplify 10 microsatellites that were identified at various distances from the canine OXTR gene. We used 94 ( 52 males, 42 females) blood samples from shelter dogs, 75 (33 males, 42 females) saliva samples from pet dogs and 12 (6 males, 6 females) captive wolf saliva samples to carry out our analyses. Significant species differences were found in the two markers closest to the OXTR gene, suggesting that this gene may have played an important part in the domestic dogs' evolution from the wolf. However, no significant, meaningful differences were found in microsatellites between good versus bad OCT performers, which suggests that other factors, such as different training and socialisation experiences, probably impacted task performance.

\section{HIGHLIGHTS}

This study revealed genomic differences between the domestic dog and the wolf. These differences were close to the oxytocin receptor gene and implicate this gene in the dog's evolution from the wolf.

Pet Behaviour Science | 2016, Vol.2, 1-15

Jessica Lee Oliva ${ }^{1}$, Yen T Wong ${ }^{2}$, Jean-Loup Rault ${ }^{3}$, Belinda Appleton ${ }^{2}$, Alan Lill ${ }^{4}$

1. School of Biological Sciences,

Monash University

2. Life and Environmental Sciences,

Deakin University, Geelong

3.Animal Welfare Science Centre,

University of Melbourne.

4. Department of Ecology, Environment and Evolution, School of Life Sciences,

La Trobe University, Melbourne

Australia.

Keywords:

dog, gene, object,

oxytocin, wolf
Although some dogs are naturally better than other dogs at solving such tasks, this study did not reveal any genomic differences between good versus poor performing domestic dogs. While further genetic studies are warranted, this suggests that other nongenetic influences may effect object choice task performance, such as the early life experiences of the dog.

\section{INTRODUCTION}

The neuropeptide, oxytocin, is commonly known for its role in mammalian bonding ( $\mathrm{Lim}$ and Young 2006). Several studies have also found an association between plasma oxytocin (Handlin et al 2001; Odendaal and Meintjes 2003), serum oxytocin (Miller et al. 2009), or urinary oxytocin (Nagsawa et al. 2009), and human-dog bonding. However, caution should be applied when interpreting these findings for two reasons. Firstly, while Odendaal and Meintjes used established chromatographic methods to measure oxytocin, Handlin et al. and Miller et al. employed enzyme immunoassay methods without prior sample extraction, which has recently been shown to be 
necessary in obtaining valid results (Christensen et al. 2014; Szeto et al. 2011). Similarly, Nagasawa and colleagues validated their methodology for measuring oxytocin in dogs' (but not human) urine using plasma samples assayed with no mention of extraction (Mitsui et al. 2011). However we can assume extraction did not take place due to the high values they obtained, typical from unextracted samples, out of the normal biological range (in humans) measured using validated methods (Christensen et al.; McCullough et al. 2013). Secondly, and more importantly, peripheral measures of oxytocin are not necessarily a reflection of central function. Indeed, studies have demonstrated that oxytocin, as well as its structurally similar neuropeptide, arginine vasopressin, do not readily cross the blood-brain barrier (Robinson 1983; Veening et al. 2010; Vorherr et al. 1968) and can be independently released in the brain and in the body (Amico et al. 1990; Engelmann et al. 2000; Ludwig and Leng 2006; Robinson and Jones 1982). An alternative method to better evaluate the effects of central oxytocin function is to administer oxytocin intranasally. Although their mechanisms of action are poorly understood (Leng and Lugwig 2016), neuropeptides administered in this way are believed to gain access to the brain, as increased levels can be found in brain dialysates (Neumann et al. 2013) and cerebrospinal fluid (CSF) (Born et al. 2002; Dal Monte et al. 2014; Rault 2016; Striepens et al. 2013) following administration. Therefore, rather than measuring the peptide itself, behaviours can be measured after peptide administration. This method has been exploited in many human studies and oxytocin is now receiving increasing attention for its role in human social cognition, as demonstrated by increasing gaze to the eye region of human faces (Guastella et al. 2008), improving perception of human movements (Keri and Benedek 2009), enhancing facial processing, emotion recognition, memory and encoding of facial stimuli (see review, Guastella and MacLeod 2012), and increasing trust (Kosfeld et al. 2005). It is important to note, however, that the effects of oxytocin have not always been pro-social; it has caused decreases in sociality under certain circumstances, for example, in experiments that involve out-groups, competition and/or rejection sensitive participants (see review, Bartz et al. 2011).

In dogs, intranasally administering oxytocin has been shown to increase positive expectations (Kis et al. 2015), decrease friendliness in response to a threatening person (Hernádi et al. 2015), increase affiliation towards owners and conspecifics (Romero et al. 2014), increase play behaviours towards conspecifics (Romero et al. 2015) and increase mutual gaze with their owners (Nagasawa et al. 2015). Our recent study involving intranasal oxytocin administration in domestic dogs (Canis familiaris) found that it also increased the ability of dogs to use human communicative gestures to find food in an object choice task (OCT) (Oliva et al. 2015). Dogs were tested on this task on two separate days, 515 days apart, once after oxytocin administration and once after saline. Order of treatments were predetermined according to group allocation, oxy-sal or sal-oxy. The task involved a human experimenter using momentary distal pointing cues to indicate the location of a hidden food reward in one of two opaque containers to the right and to the left of her. Results showed that the dogs that received oxytocin in their first testing session (oxy-sal dogs) outperformed dogs that received saline, and this performance was maintained up to 15 days later, in the absence of further oxytocin administration, where they performed equally as well as dogs receiving oxytocin in their second session (sal-oxy dogs) (Oliva et al. 2015).

We suggest that changes in the canine oxytocinergic system may have been integral to the evolution of the domestic dog from the wolf (Canis lupus), the phylogenetically closest species to the domestic dog (Wang et al. 2013). Evidence supporting this theory comes from studies which have shown that whilst domesticated dogs perform well on OCTs employing relatively difficult momentary distal pointing cues (Miklósi et al. 2005; Soproni et al. 2002; Virányi et al. 2008), hand-reared wolves do not (Miklósi et al. 2003; Virányi et al.), at least without extensive training (Virányi et al.). Moreover, extensive socialization with humans does not further enhance domestic dogs' ability to use momentary distal pointing cues at four months old. This is evidenced by the fact that, with hand-reared domestic dogs who were separated from their mothers a few days after birth and intensively hand-reared by humans, and pet dogs who remained with their mothers for several weeks after birth before being adopted out to a human family, performed equally well on OCTs employing this cue. The same 
intensive socialization did not help hand-reared wolves of the same age perform the same task as they demonstrated an ability no better than chance. However, these wolves did demonstrate an ability to learn this cue over time and at age eleven months were able to perform at above chance level, comparable to naïve dogs of the same age (Virányi et al.).

Further evidence for the important influence of learning in wolves comes from a study by Udell et al. (2008b) which demonstrated that when adult pet dogs and adult hand-reared wolves were both tested in an outdoor enclosure (an environment familiar to wolves but unfamiliar to dogs) using momentary distal pointing cues given by a familiar experimenter, wolves significantly outperformed dogs. However, pet dogs that were tested indoors, even by an unfamiliar experimenter, performed as well as the wolves tested outdoors. This was not true for shelter dogs tested indoors. The reason that the wolves in Udell et al.'s study were readily able to use this cue, while the wolves in Miklósi (2003) et al.'s study who were tested in a similar environment were not, may be due to the fact that, as pointed out by Hare et al. (2010, p.e6): "the wolves that Udell and colleagues tested probably had received previous training" and Udell and Wynne (2010) agree with this suggestion in a later publication. But this does not explain why the dogs in this study performed so poorly.

Ried (2009) has suggested that the olfactory, auditory and visual contact with conspecifics in this experimental set-up may have been unfairly distracting to the dogs who were likely to be unfamiliar with the other dogs in the experiment, compared with the wolves who were used to their conspecific companions. This would suggest that an important factor in performing accurately on an OCT is a familiar or natural environment. Indeed, results from dogs tested in an unnatural environment (Kirchhofer et al. 2012; Udell et al. 2008b; Udell et al. 2010b) (behind a fence, outside or in a shelter) suggest that their ability can be compromised by environmental factors that probably impact on the animals' level of stress.

Nagasawa et al. (2015)'s study has provided further evidence supporting the claim that the oxytocinergic system may have been shaped through the process of domestication in a way which allowed for dogs to both communicate and bond with humans. This was evidenced by the fact that mutual dog-owner gaze (which increased measures of oxytocin in the owner's urine) increased in female dogs following intranasal oxytocin administration and was not achieved with hand-raised wolves, who only rarely demonstrated mutual gazing with their owners.

Geneticists are continuing to investigate the association between human social cognition and the oxytocin receptor (OXTR) gene. For example, single nucleotide polymorphisms (SNPs) have been associated with attachment style (Chen et al. 2011; Denes 2015), and autism (Jacob et al. 2007; Wu et al. 2005), as well as less extreme disorders of social functioning such as the presentation of callous-unemotional traits and conduct problems (Dadds et al. 2014). Associations have also been found between OXTR gene SNPs and mothers' sensitivity to their toddlers (Bakermans-Kranenburg and van Ijzendoorn 2008; Riem et al. 2011), empathy and stress (Rodrigues et al. 2009), optimism, personal mastery and self-esteem (Saphire-Bernstein et al. 2011), positive affect and non-verbal intelligence (Lucht et al. 2009), and sociality (Tost et al. 2010). In addition, associations have been found between OXTR gene SNPs and amounts of oxytocinergic-rich connections in the hypothalamus and connections between the hypothalamus and both the amygdala and the dorsal anterior cingulate cortex (Tost et al. 2010). Whilst there is strong evidence to support variants of this gene functioning differently in humans, there is little evidence to date supporting differing effects of variants of this gene in dogs. It is reasonable to assume that this is likely, however, given the vast array of homologous human-dog phenotypes that have been associated with analogous genes in the two species (see reviews, Parker et al. 2010; Sutter and Ostrander 2004).

Allelic variability of the canine OXTR gene is poorly known. One study investigated SNPs within the OXTR gene in dogs and found associations with proximityseeking and friendliness in two different dog breeds (Kis et al. 2014). However, the SNP associated with friendliness was associated with opposing phenotypes in the two different breeds. Similar findings have been found with OXTR gene SNPs which are associated with autism affecting people of different ethnicities 
differently (Jacob et al. 2007; Wu et al. 2005). An alternative approach to increase the probability of finding genomic differences, especially in a relative small sample of dogs of different breeds, is to look at microsatellites close to the gene of interest. Microsatellites are short tandem repeats that can occur within both the coding and non-coding (un-translated) regions of the genome and have been used extensively to demonstrate association between a genomic location and a trait (see review, Montaldo and Meza-Herrera 1998).

Despite the fact that dogs generally perform well on OCTs when tested in a natural environment, many studies report a wide range of individual variability in performance (Agnetta et al. 2000; Hare et al. 2002; Miklósi et al. 1998; Udell et al. 2008a; Udell et al. 2008b, Udell et al. 2010b; Virányi et al. 2008; Wobber et al. 2009) and this may reflect differences in the OXTR gene. In dogs, the OXTR gene is 2.41 million base pairs long and located on chromosome 20 at position 9.36 million base pairs within the genome (NCBI 2012). We used microsatellites located at different distances from the OXTR gene (refer to Table 1) to investigate genetic association with OCT performance phenotypes. Given the species differences demonstrated in several studies (Hare et al. 2002; Miklósi et al. 2003; Udell et al. 2008b; Virányi et al. 2008), the objectives of the current study were to search for genotypic differences near the OXTR gene between: i) good and poor OCT performers and ii) domestic dogs and wolves.

\section{METHODS}

\section{Study animals}

Owners of 75 pet dogs (33 males, 42 females) volunteered their dogs for a study investigating the effect of intranasal oxytocin on dogs' performance on an OCT. Dogs were required to be more than 12 months old, healthy, and not pregnant or lactating. No restriction was put on breed, as this was too difficult to control using pet and shelter dogs whose breeds were often mixed and not confirmable. Recruitment took place through poster advertisements at university campuses and on university e-newsletters and social media websites. To increase the effective sample size of domestic dogs for genetic analysis, an additional 94 blood samples (52 from males, 42 from females) were obtained from the Animal Aid animal shelter, Coldstream, Victoria, Australia. Blood, rather than saliva, was used as a matter of convenience as $0.5-1 \mathrm{ml}$ blood samples were routinely collected from shelter dogs to test for heart-worm, and it was easy to take an extra 2-2.5 $\mathrm{ml}$ for the purposes of our study. Twelve samples of wolf saliva were supplied by Wolf Park, Battle Ground, Indiana, USA. All wolves were a mix of the subspecies: Arctos, Occidetalis and/or Nubilus, and had been human-reared from 10-14 days of age and whilst were living as a pack in a large outdoor enclosure, still interacted with humans on a daily basis. The study was approved by the Monash University School of Biological Sciences Animal Ethics Committee (BSCI/2013/07).

\section{Materials}

Intranasal treatments containing either oxytocin dissolved in saline, or containing saline only were stored in frozen tubes labelled ' $\mathrm{A}$ ' or ' $\mathrm{B}$ '. Both the experimenter and the pet dog's owner were 'blind' as to which tubes contained which treatments. Twenty-four international units of oxytocin (Auspep, Melbourne, $\mathrm{AU})$ dissolved in a $0.1 \mathrm{ml}$ saline solution was administered to the nostrils of the dogs via a Mucosal Atomizer Device connected to a $1 \mathrm{~mL}$ syringe, with a half dose $(0.05 \mathrm{ml})$ in each nostril. Dogs received each treatment on a separate testing day in a predetermined, pseudo-randomized and counterbalanced order. Oragene animal swabs (Canada) were used to collect deoxyribonucleic acid (DNA) samples in saliva of the pet dogs involved in the study, as well as from the wolves. Approximately $2-2.5 \mathrm{ml}$ blood samples were drawn from the cephalic or jugular vein of the shelter dogs. Prior to collection, the area was clipped with surgical blades and cleaned with methylated spirits. Ten tandem repeats were visually identified close to the dog OXTR gene (NCBI 2012) and primers were designed using the online program, Primer 3 (Untergasser et al. 2012; see Table 1). 'Lamb puffs' were used as dog treats in the OCT and were concealed using four identical, opaque spaniel bowls. Pen and paper were used to score performance (correct/incorrect choice of concealed food reward) on the OCT. 


\begin{tabular}{|cccccccc|}
\hline Primer & $\begin{array}{c}\text { Location } \\
\text { (base pairs) }\end{array}$ & $\begin{array}{c}\text { Period } \\
\text { size }\end{array}$ & $\begin{array}{c}\text { Copy } \\
\text { number }\end{array}$ & A & C & G & T \\
\hline 1 & 2.04 million & 4 & 25.3 & 77 & 0 & 22 & 0 \\
2 & 2.49 million & 4 & 21 & 53 & 0 & 46 & 0 \\
3 & 8.51 million & 3 & 20.3 & 0 & 32 & 0 & 67 \\
4 & 8.53 million & 2 & 28.5 & 50 & 49 & 0 & 0 \\
5 & 9.11 million & 2 & 27 & 0 & 0 & 50 & 49 \\
6 & 9.66 million & 2 & 22 & 0 & 0 & 50 & 50 \\
7 & 9.74 million & 4 & 23 & 0 & 25 & 0 & 74 \\
8 & 9.94 million & 2 & 26.5 & 50 & 47 & 0 & 1 \\
9 & 15.97 million & 3 & 21.7 & 0 & 32 & 0 & 67 \\
10 & 15.98 million & 2 & 25 & 50 & 0 & 0 & 50 \\
\hline
\end{tabular}

Table 1. Microsatellites and their distances from OXTR gene within the canine genome. The OXTR gene is located at 9.36 million base pairs within the genome (NCBI 2012).

\section{Procedure}

When the pet dog arrived at the testing location for their first testing session, he/she was administered an intranasal treatment of saline or oxytocin, depending on which group he/she has been pseudo-randomly assigned to: those that received oxytocin in their first session and saline in their second session (oxy-sal) or vice versa (sal-oxy). When the dog arrived for their second session, they received the other intranasal treatment and there was a 5-15 days washout period between sessions. After the intranasal administration a swab was rubbed against the inside of the animals' cheeks for approximately 30 seconds and stored in a fridge at the testing location (this usually occurred in session 1) before being transported to the laboratory for genetic analysis. The dog was required to wait for 45 minutes after receiving the nasal spray before the testing began. During this time the dog was free to roam the testing room, interact with its owner and/or the experimenter, or wander outside. After the 45 minute waiting period lapsed, the OCT commenced, which involved a) pre-training (before each 10 trial block of the OCT proper): four correct trials in a row where the dog was shown a food treat being dropped into one of two dog bowls, either side of the experimenter (delivered using the ipsilateral hand from a kneeling position, $75 \mathrm{~cm}$ from the target) (b) 20 trials (block 1 and block 3) where the dog was given a momentary distal pointing cue (a 1-2 second point delivered using the ipsilateral index finger from the same kneeling position) to indicate the location of the hidden food reward located in one of the two dog bowls and (c) 20 trials (block 2 and block 4) using a gaze cue (a 1-2 second gaze shift delivered from the same kneeling position, keeping the head straight). Five control trials per block, where no cue was given, were also delivered to ensure the dogs were not relying on scent to solve the task. The task usually lasted between 45 and 60 minutes and was carried out by the experimenter with the help of the owner, who called the dog back to the starting position between trials and restrained it until the experimenter said the release word "OK". The experimenter recorded the score for each trial as either correct (if the dog approached the bowl with the hidden food treat) or incorrect (if the dog approached the empty bowl or the experimenter) before starting the next trial. Trials were also considered incorrect if the dog made no choice but was 
deemed motivated to complete the task by participating when two of the easier pre-training cues were then given as a test of motivation. For the purposes of the current study, only the momentary distal pointing data were analysed because dogs were not able to use the gazing cue above chance levels (Oliva et al. 2015). This data is the same as that which was published in Oliva et al.

\section{Sample preparation and polymerase chain reaction}

Ninety-four genomic DNA samples were extracted from shelter dogs' blood using AxyPrep Blood Genomic DNA miniprep kit (Axygen, USA). Eightyseven saliva samples were obtained from pet dogs and wolves using Oragene ANIMAL/saliva kits (Oragene, Canada). Polymerase chain reaction (PCR) was performed in a total of $12.5 \mu \mathrm{l}$ volume reactions in a 96 well PCR plate (Interpath Services, Australia). Each well contained a $6.25 \mu 1$ aliquot of genomic DNA and a $6.25 \mu \mathrm{l}$ PCR reagent mix. The PCR reagent mix contained distilled water, $2.5 \mathrm{mM} \mathrm{MgCl}$, $1 \mathrm{mM}$ deoxynucleotide triphosphates (dNTPs), 1x PCR buffer, $1 \mathrm{U}$ of taq polymerase, $0.28 \mu \mathrm{M}$ fluorescent-labelled M13(-21) primer (FAM, VIC, PET or NED) (Promega, USA), $0.072 \mu \mathrm{M}$ forward primer and $0.28 \mu \mathrm{M}$ reverse primer (Macrogen, Korea) per reaction. For all the forward primers the $5^{\prime}$ end was modified with a M13(21) universal sequence tag (5'-TGTAAAACGGCCAGT$\left.3^{\prime}\right)$ to enable the incorporation of the universal fluorescent labelled M13(-21) primer for detection on ABI3730 capillary instrument (Macrogen, Korea) (Schuelke, 2000). All PCRs were performed with a Veriti 96 well fast thermal cycler (Applied Biosystem, Australia). The thermal cycler was programmed to 1 cycle of $5 \mathrm{~min}$ at $94^{\circ} \mathrm{C}$ as initial hot start, then $30 \mathrm{sec}$ at $94^{\circ} \mathrm{C}$, annealing step of $30 \mathrm{sec}$ at $55-65^{\circ} \mathrm{C}$ and extension step of $40 \mathrm{sec}$ at $72^{\circ} \mathrm{C}$. This was followed by a repeat of the cycle above 30 times and then by 8 extra cycles to ensure the oligo dye attached to the maximum amount of fragments. Then followed denaturation at $94^{\circ} \mathrm{C}$ for 30 sec, annealing at $53^{\circ} \mathrm{C}$ for $45 \mathrm{sec}$ and extension at $72^{\circ} \mathrm{C}$ for $45 \mathrm{sec}$. Finally, 1 cycle of $10 \mathrm{~min}$ at $72^{\circ} \mathrm{C}$ was run for final extension and held at $14^{\circ} \mathrm{C}$.

\section{Electrophoresis of amplified products}

After amplification, a $2 \mu \mathrm{l}$ aliquot of the amplified PCR product was combined with $2 \mu$ l of loading buffer $(0.4 \%$ $(\mathrm{w} / \mathrm{v})$ bromo-phenol blue, 0.5M EDTA and $6 \mathrm{ml}$ of glycerol) and analyzed directly on $1 \%(\mathrm{w} / \mathrm{v})$ agarose LE (Benchmark Scientific, Australia) gel in 1 x TAE buffer (50 mM Tris acetate, $1 \mathrm{mM}$ EDTA). Two $\mu \mathrm{l}$ of Hyper ladder I (Bioline, Australia) was used as a size marker to compare the molecular weight of the amplified products. Gels were run at 100 volts for 25 mins and the gel images were documented by Molecular Imager CHemi Doc XRS4 Imaging system (Syngene, UK). Then, $4 \mu \mathrm{l}$ of each of four different microsatellite amplicons were pooled for the same animal. These pooled samples were combined into a master 96 well plate and sequenced by Macrogen (Korea).

\section{Data analysis}

Deoxyribonucleic acid fragment analysis was carried out using nucleic acid analysis software (Toonan and Hughes 2001). This software allowed fast analysis of the multiplexed microsatellite markers. Contingency tables were used to compare the case and control canine with the risk and wild type genotypes. This allowed assessment of the degree of association of performance and species traits. In line with recommendations by Campbell (2007), contingency tables with expected frequencies $>1$ were analysed with an N-1 $\chi^{2}$, and contingency tables with expected frequencies $<1$ were analysed with a Fisher-Irwin test by Irwin's rule. These analyses were carried out using SPSS version 22.0 ( SPSS IBM, New York, USA, 2013), following methods from Weaver (2013). Given the observed effect of intranasal oxytocin on performance in the OCT which lasted across the sessions for dogs that received oxytocin in session 1 (Oliva et al. 2015), we separated good performing versus poor performing dogs in the following three ways so as not to confound the results. Firstly, we looked at only the group of dogs that received saline in their first testing session (sal-oxy dogs) and used performance data from that session only. Secondly, because there was no difference between the performance level of the two groups of dogs in session 2 (with oxy-sal dogs having maintained their enhanced performance from session 1, and sal-oxy dogs having their performance enhanced by oxytocin in session 2), we used "oxytocin-induced performance" data (i.e. session 2 data) from all dogs in the study. We considered good performers as dogs that scored $\geq 18 / 20$ 
correct points, and poor performers as those that scored $\leq 12 / 20$ correct points. Dogs scoring between 13$17 / 20$ were excluded from the analysis. Finally, we wanted to see if some dogs were more susceptible than other dogs to the oxytocin treatment and so analysed difference scores in performance between the two sessions for sal-oxy dogs only. We considered high oxytocin responders to be dogs that improved their performance by 3-7 points between sessions, and poor responders as those whose performance remained the same, or declined, between sessions. Dogs scoring a difference of 1-2 points between sessions were excluded from the analysis.

\section{RESULTS}

Primers 9-10 were not analysed because they did not anneal correctly to the target template. As such, only results pertaining to primers 1-8 are shown below. Tables 2-4 show the microsatellite markers identified for the analyses.

\begin{tabular}{|cccc|}
\hline Primer & $N$-1 $\chi^{2}$ & $p$-value & $\begin{array}{c}\text { Fisher-Irwin } \\
p \text {-value }\end{array}$ \\
\hline 1 & - & - & 1.00 \\
2 & - & - & 1.00 \\
3 & - & - & 0.42 \\
4 & - & - & 1.00 \\
5 & - & - & 1.00 \\
6 & - & - & 1.00 \\
7 & 1.54 & 0.21 & - \\
8 & - & - & 1.00 \\
\hline
\end{tabular}

Table 2. Microsatellite markers and session 1 performance association analysis by contingency N-1 $\chi^{2}$ or Fisher-Irwin test by Irwin's rule.

Within the sal-oxy group of dogs, there were 13 poor performers, five good performers, and 15 mid-range performers that were excluded from the analysis. There was no significant association between session 1 performance and any of the primers (Table 2).

In session 2, there were 10 poor performers (5 oxy-sal dogs and 5 sal-oxy dogs), 28 good performers (19 oxysal dogs and 9 sal-oxy dogs), and 24 mid-range performers ( 8 oxy-sal dogs and 16 sal-oxy dogs) that were excluded from the analysis. There was no significant association between session 2 performance and any of the primers (Table 3).

\begin{tabular}{|cccc|}
\hline Primer & $N-1 \chi^{2}$ & $p$-value & $\begin{array}{c}\text { Fisher-Irwin } \\
p \text {-value }\end{array}$ \\
\hline 1 & - & - & 1.00 \\
2 & 0.63 & 0.43 & - \\
3 & - & - & 1.00 \\
4 & 0.47 & 0.50 & - \\
5 & 0.58 & 0.45 & - \\
6 & - & - & 1.00 \\
7 & 0.025 & 0.88 & - \\
8 & 1.56 & 0.21 & - \\
\hline
\end{tabular}

Table 3. Microsatellite markers and session 2 performance association analysis by contingency $\mathrm{N}-1 \chi^{2}$ or Fisher-Irwin test by Irwin's rule.

When evaluating difference scores between sessions for the sal-oxy group of dogs, there were 10 poor oxytocin responders, 13 high responders, and eight mid-range responders that were excluded from the analysis. There was no significant association between oxytocin response and any of the primers (Table 4).

\begin{tabular}{|cccc|}
\hline Primer & $N-1 \chi^{2}$ & $p$-value & $\begin{array}{c}\text { Fisher-Irwin } \\
p \text {-value }\end{array}$ \\
\hline 1 & - & - & 1.00 \\
2 & 2.62 & 0.11 & - \\
3 & - & - & 1.00 \\
4 & 0.47 & 0.50 & - \\
5 & - & - & 1.00 \\
6 & - & - & 1.00 \\
7 & 1.78 & 0.18 & - \\
8 & 0.80 & 0.37 & - \\
\hline
\end{tabular}

Table 4. Microsatellite markers and difference in performance between sessions association analysis by contingency $N-1 \chi^{2}$ or Fisher-Irwin test by Irwin's rule.

Finally, we tested whether there were any differences between the OXTR gene of the domestic dog and that of the wolf. Table 5 shows the microsatellite markers identified for the analysis. Tables 6-7 show the contingency tables for the significant analyses.

There was a significant association between species and primer $5, \mathrm{p}=0.038$ (Table 5). Odds ratio for the allele (risk/wild-type $)=12.00$, indicating that a canine with the risk allele is twelve times more likely to be a dog than a wolf, than if it has a wild-type allele. 


\begin{tabular}{|cccc|}
\hline Primer & $N-1 \chi^{2}$ & $p$-value & $\begin{array}{c}\text { Fisher-Irwin } \\
p \text {-value }\end{array}$ \\
\hline 1 & 1.90 & 0.17 & - \\
2 & - & - & 0.070 \\
3 & 3.24 & 0.072 & - \\
4 & - & - & 1.00 \\
5 & - & - & $\mathbf{0 . 0 3 8}^{\star}$ \\
6 & 4.93 & $\mathbf{0 . 0 2 6 ^ { * }}$ & - \\
7 & 0.036 & 0.85 & - \\
8 & - & - & 1.00 \\
\hline
\end{tabular}

Table 5. Microsatellite markers and species association analysis by contingency $N-1 \chi^{2}$ or Fisher-Irwin test by Irwin's rule. ${ }^{*} p<.05$

\begin{tabular}{|ccc|}
\hline primer 5 & Risk & Wild-type \\
\hline Case (dog) & 44 & 11 \\
Control (wolf) & 1 & 3 \\
\hline primer 6 & Risk & Wild-type \\
\hline Case (dog) & 33 & 37 \\
Control (wolf) & 0 & 6 \\
\hline
\end{tabular}

Table 6. Contingency table for primer 5 and primer 6.

There was also a significant association between species and primer $6, p=0.026$ (Table 5). Odds ratio for allele (risk/wild-type $)=11.61$, indicating that a canine with the risk allele is almost twelve times more likely to be a dog than a wolf, than if it has a wild-type allele.

\section{DISCUSSION}

The study revealed significant species differences between dogs and wolves, using 2 microsatellite primers close to the OXTR gene. Considering that the domestication of the dog occurred approximately 32,000 years ago (Wang et al. 2013), the identified allelic differences between dog and wolf are likely to reflect an old mutation. In an old mutation under strong selection, we expect linkage disequilibrium to decay rapidly as we move away from the causative gene. Therefore, we would expect to see a strong association between genetic variation and species near the OXTR gene and no association when we move along the chromosome away from the gene. This study found that two markers close to the OXTR gene, primers 5 and 6, were different in dogs and wolves. Of all the primers, these are the two closest to the OXTR gene at positions 9.11 million and 9.66 million base pairs, respectively, supporting the above-hypothesized strong selection. For primer 5, the wolves did not demonstrate a common allele, probably due to the very small number of wolf samples that amplified (refer to Table 6). By examining the raw data, we see that all of these samples expressed a different microsatellite size, one of which was the risk allele. For primer 6 , the risk allele was not present in any of the 6 wolf samples that amplified and could be analysed (refer to Table 7). Due to the small sample sizes used in the current study, it is difficult to draw any firm conclusions, however, given that we are seeing significance in markers closest to the gene and an absence of significance in markers further away from it, these findings certainly warrant further research to be carried out with a larger sample of wolf DNA. Another limitation of our study was that the blood samples from shelter dogs, and the saliva samples from pet dogs and wolves, were analysed in two separate batches with no blood-saliva samples that had come from the same canine which we could use to standardize the samples. As such, while unexpected, there is no way of knowing if there were biases in the samples and therefore, future studies should be mindful to collect additional samples from a subgroup of animals on which to carry out this standardization. Future studies could also utilize other markers in this region to map the association more accurately e.g. SNPs.

The current study failed to detect genomic differences in good- versus poor -performing dogs on an OCT. This may be because we were not focusing closely enough on the OXTR gene itself. Due to the novelty of the study and the unknown variation within the canine OXTR gene, rather than looking within the gene, we looked at microsatellites close to the gene to increase the chance of finding any association. However, it is possible that we have missed a genetic difference within the gene itself that differentiates good from poor OCT performing domestic dogs. Dog breed, which was not controlled in the current study, may also affect behavioural phenotypes as observed by Kis et al. (2014) with respect to friendliness, and Jakovcevic et al. (2010) with respect to gaze towards the human face. Lastly, the transmembrane enzyme, CD38, is attracting research interest, as variations of this gene have been 
linked with oxytocin secretion and associated social behaviours (see review, Macdonald 2012). Hence, future studies should also investigate this gene, in addition to the OXTR gene, when examining phenotypes believed to be governed by the oxytocin system.

Alternatively, the lack of significant disparities between good and poor performances may be due to the fact these differences are not genetic in nature. For example, there may have been differences in the individual dogs' learning and training. Indeed, dogs seem to possess a degree of cognitive flexibility in their use of human cues, for example, learning not to follow human pointing in an OCT when it is no longer reinforcing, and can even learn to avoid a pointed at object if a non pointed at object suddenly becomes the reinforcer (Elgier et al. 2009). Furthermore, if dogs have learned to associate the hidden food reward in an OCT with a physical (non-human) cue this may then hinder their ability to successfully use a human pointing cue (Elgier et al. 2012). Prior training and learning was not investigated in the current study but may be responsible for a dogs' level of performance.

Socialisation history is also an important factor which may explain individual differences in OCT performances. For example, early stimulation of the oxytocinergic system, for example, via hormonal imprinting, has been shown to have implications for function in later life (see review, Csaba 2000). As Csaba explains, a critical window exists in the first few days after birth in which this hormonal imprinting can occur. The process is defined by the provocation of a hormone receptor-to-be by a circulating hormone. If this process does not occur, the receptor does not mature and is unable to bind with the hormone in a suitable quantity. For most receptor cells, this inability is life-long and passed down to daughter cells (except in the brain where most cells do not differentiate) and in some cases, even to offspring of the animal. In his review, Csaba (2008) surmises that this is a result of a change in heritable DNA methylation; however, the exact mechanism behind hormonal imprinting remains unknown. Faulty imprinting can occur as a result of a lack of the appropriate hormone which reduces receptor density (Csaba 2008). Csaba (2000; 2008) supports the notion of imprinting as a "memory-like process" (Csaba 2000, p. 409) in which short repeated bouts of exposure result in greater imprinting than one single, long exposure.

Faulty imprinting likely explains why adult rats demonstrate significantly less oxytocin or vasopressin receptors in the central nucleus of the amygdalae and the bed nucleus of the stria terminalis after receiving low levels of maternal licking and grooming as pups, compared to those who received high levels of maternal licking and grooming (Francis et al. 2002). Tanaka et al. (2010) also demonstrated similar findings whereby isolation-reared rat pups have fewer immunoreactive vasopressin cells (males) in the dorsal, medial parvocellular part of the paraventricular nucleus of the hypothalamus, than socially-reared pups, and fewer oxytocin cells (females) in the ventral, medial parvocellular part of the paraventricular nucleus of the hypothalamus. Isolation-reared males were also more cautious than socially-reared ones in an elevated plus-maze and neither male nor female rat pups displayed signs of familiarity during a social recognition test.

Faulty imprinting may also explain findings from a study of nursery-reared rhesus monkeys that displayed significantly less oxytocin in their cerebrospinal fluid and less affiliative and more aggressive and abnormal repetitive behaviours compared to mother-reared rhesus monkeys. Moreover, a retrospective study found that women with a history of childhood abuse, particularly repeated and emotional abuse, displayed lower levels of oxytocin in their cerebrospinal fluid in adulthood (Heim et al. 2009).

In addition to this critical period for hormonal imprinting, there is another critical period for socialisation in birds and mammals, in which they willingly accept other animals, including humans, into their environment (Scott 1962). If socialisation with humans does not occur within a dogs' critical period, 310 weeks of age (Scott), a fear of humans may override their cognitive capacity to use humans' social cues in a beneficial way. This lead Udell et al. (2010a) to the 'two stage hypothesis' which states that sensitivity to human cues requires i) interactions with, and acceptance of, humans during the sensitive period of the canid's social development, followed by ii) learning, through classical 
and operant conditioning, to pair human gestures with the acquisition of something favourable. This has been supported by a study demonstrating better OCT performance by pet dogs versus purpose-bred research dogs that have been socialised to humans at a young age, but who do not cohabit with them and have relatively less contact with them than pet dogs have with their owners (Lazarowski and Dorman 2015).

All the dogs in our study were currently-owned pets whose backgrounds were not investigated, however, while some had come from responsible breeders, others were shelter 'rescues', and others came from pet shops renowned in Australia for selling puppies obtained from puppy farms (RSPCA 2010). Dogs born into poor environments, such as puppy farms, may not have experienced adequate imprinting of oxytocin to its receptors, or adequate socialisation within the critical period due to deprivation of positive social experiences, and may have comprised the poor performers in our study for this reason. This possibility requires further research from future studies that should take dogs' socialisation backgrounds into account.

\section{CONCLUSIONS}

By measuring microsatellites close to the OXTR gene in samples of domestic dogs and wolves, this study provides evidence that mutations in this gene may have played a part in the domestic dog's evolution from the wolf. The study did not, however, produce evidence for the same mutations underlying dogs' varying performance on the OCT task.

\section{ACKNOWLEDGEMENTS}

We would like to thank Animal Aid, Coldstream, Victoria, Australia and Wolf Park, Battle Ground, Indiana for supplying DNA samples.

\section{REFERENCES}

Agnetta B., Hare B., Tomasello M. 2000. Cues to food location that domestic dogs (Canis familiaris) of different ages do and do not use. Animal Cognition 3: 107-112.
Amico, J. A., Challinor, S. M., Cameron, J. L. 1990. Pattern of Oxytocin Concentrations in the Plasma and Cerebrospinal Fluid of Lactating Rhesus Monkeys (Macaca mulatto): Evidence for Functionally Independent Oxytocinergic Pathways in Primates. Journal of Clinical Endocrinology and Metabolism 71(6): 1531-1535.

Bakermans-Kranenburg M.J., van Ijzendoorn M.H. 2008. Oxytocin receptor (OXTR) and serotonin transporter (5-HTT) genes associated with observed parenting. Social Cognitive and Affective Neuroscience 3(2): 128-134. doi: 10.1093/scan/nsn004

Bartz J.A., Zaki J., Bolger N., Ochsner K.N. 2011. Social effects of oxytocin in humans: context and person matter. Trends in Cognitive Science 15(7): 301-309.

Born J., Lange T., Kern W., McGregor G.P., Bickel U., Fehm H.L. 2002. Sniffing neuropeptides: a transnasal approach to the human brain. Nature Neuroscience 5(6): 514-516.

Campbell I. 2007. Chi-squared and Fisher-Irwin tests of two-by-two tables with small sample recommendations. Statistics in Medicine 26(19): 36613675. doi: 10.1002/sim.2832

Chen F.S., Barth M.E., Johnson S.L., Gotlib I.H., Johnson, S.C. 2011. Oxytocin receptor (OXTR) polymorphisms and attachment in human infants. Frontiers in Psychology 2. doi: 10.3389/fpsyg.2011.00200

Christensen, J. C., Shiyanov, P. A., Estepp, J. R., Schlager, J. L. 2014. Lack of association between human plasma oxytocin and interpersonal trust in a prisoner's dilemma paradigm. PLoS ONE 9(12): e116172. doi:10.1371/journal.pone.0116172

Csaba G. 2000. Hormonal imprinting: its role during the evolution and development of hormones and receptors. Cell Biology International 24(7): 407-414. doi: 10.1006/cbir.2000.0507

Csaba G. 2008. Hormonal imprinting: phylogeny, ontogeny, diseases and possible role in present-day human evolution. Cell Biochemistry and Function 26(1): 1-10. doi: 10.1002/cbf.1412 
Dadds M.R., Moul C., Cauchi A., Dobson-Stone C., Hawes D.J., Brennan J., Urwin R., Ebstein R.E. 2014. Polymorphisms in the oxytocin receptor gene are associated with the development of psychopathy. Developmental Psychopathology 26(1): 21-31. doi: 10.1017/S0954579413000485

Dal Monte O., Noble P. L., Turchi J., Cummins A., Averbeck B.B. 2014. CSF and blood oxytocin concentration changes following intranasal delivery in Macaque. PLoS ONE 9(8): e103677. doi: 10.1371/journal.pone.0103677

Denes A. 2015. Genetic and individual influences on predictors of disclosure: exploring variation in the oxytocin receptor gene and attachment security. Communication Monographs 82(1): 113-133.

Elgier, A. M., Jakovcevic, A., Barrera, G., Mustaca, A. E., Bentosela, M. 2009. Communication between domestic dogs (Canis familiaris) and humans: dogs are good learners. Behavioural processes 81(3): 402-408. doi: 10.1016/j.beproc.2009.03.017

Elgier, A. M., Jakovcevic, A., Mustaca, A. E., Bentosela, M. 2012. Pointing following in dogs: are simple or complex cognitive mechanisms involved? Animal Cognition 15: 1111-1119. doi: 10.1007/s10071-012-0534-6

Engelmann M., Wotjak C.T., Ebner K., Landgraf R. 2000. Behavioural impact of intraseptally released vasopressin and oxytocin in rats. Experimental Physiology 85S: 125S-130S.

Francis D.D., Young L.J., Meaney M.J., Insel T.R. 2002. Naturally occurring differences in maternal care are associated with the expression of oxytocin and vasopressin (V1a) receptors: gender differences. Journal of Neuroendocrinology 14(5): 349-353.

Guastella A.J., MacLeod C. 2012. A critical review of the influence of oxytocin nasal spray on social cognition in humans: evidence and future directions. Hormones and Behavior 61(3): 410-418. doi: 10.1016/j.yhbeh.2012.01.002
Guastella A.J., Mitchell P.B., Dadds M.R. 2008. Oxytocin increases gaze to the eye region of human faces. Biological Psychiatry 63(1): 3-5. doi: 10.1016/j.biopsych.2007.06.026

Handlin L., Hydbring-Sandberg E., Nilsson A., Ejdebäck M., Jansson A., Uvnäs-Moberg K. 2011. Shortterm interaction between dogs and their owners: effects of oxytocin, cortisol, insulin and heart-rate - an exploratory study. Anthrozoös 24(3): 301-315.

Hare B., Brown M., Williamson C., Tomasello M. 2002. The domestication of social cognition in dogs. Science 298(5598): 1634-1636. doi: 10.1126/science.1072702

Hare, B., Rosati, A., Kaminski, J., Bräuer, J., Call, J., Tomasello, M. 2010. The domestication hypothesis for dogs' skills with human communication: a response to Udell et al. (2008) and Wynne et al. (2008). Animal Behaviour 79, e1-e6.

Heim C., Young L.J., Newport D.J., Mletzko T., Miller A.H., Nemeroff C.B. 2009. Lower CSF oxytocin concentrations in women with a history of childhood abuse. Molecular Psychiatry 14(10): 954-958. doi: 10.1038/mp.2008.112

Hernádi A., Kis A., Kanizsár O., Tóth K., Miklósi B., Topál J. 2015. Intranasally administered oxytocin affects how dogs (Canis familiaris) react to the threatening approach of their owner and an unfamiliar experimenter. Behavioural Processes 119: 1-5. doi: 10.1016/j.beproc.2015.07.001

IBM Corp. 2013. SPSS Statistics for Windows, Version 22.0. IBM Corp., Armonk.

Jacob S., Brune C.W., Carter C.S., Leventhal B.L., Lord C., Cook E.H. Jr. 2007. Association of the oxytocin receptor gene (OXTR) in Caucasian children and adolescents with autism. Neuroscience Letters 417(1): 6-9. doi: 10.1016/j.neulet.2007.02.001

Jakovcevic A., Elgier A.M., Mustaca A.E., Bentosela M. 2010. Breed differences in dogs' (Canis familiaris) gaze to the human face. Behavioural Processes 84: 602-607. doi: 10.1016/j.beproc.2010.04.003 
Keri S., Benedek G. 2009. Oxytocin enhances the perception of biological motion in humans. Cognitive Affective and Behavioral Neuroscience 9(3): 237-241. doi: 10.3758/CABN.9.3.237

Kirchhofer, K. C., Zimmermann, F., Kaminski, J., Tomasello, M. 2012. Dogs (Canis familiaris), but not chimpanzees (Pan troglodytes), understand imperative pointing. PloS one 7(2), e30913. doi: 10.1371/journal.pone.0030913

Kis A., Bence M., Lakatos G., Pergel E., Turcsán B., Pluijmakers J., Vas J., Elek Z., Brúder I., Földi L., Sasvári-Székely M., Miklósi A., Rónai Z., Kubinyi E. 2014. Oxytocin receptor gene polymorphisms are associated with human directed social behavior in dogs (Canis familiaris). PloS one 9(1): e83993. doi: 10.1371/journal.pone.0083993

Kis A., Hernádi A., Kanizsár O., Gácsi M., Topál J. 2015. Oxytocin induces positive expectations about ambivalent stimuli (cognitive bias) in dogs. Hormones and Behavior 69: 1-7. doi: 10.1016/j.yhbeh.2014.12.004

Kosfeld M., Heinrichs M., Zak P.J., Fischbacher U., Fehr E. 2005. Oxytocin increases trust in humans. Nature 435(7042): 673-676. doi: 10.1038/nature03701

Lazarowski, L., Dorman, D.C. 2015. A comparison of pet and purpose-bred research dog (Canis familiaris) performance on human-guided object-choice tasks. Behavioural Processes 110: 60-67. doi: 10.1016/j.beproc.2014.09.021

Leng, G., Ludwig, M. 2016. Intranasal Oxytocin: Myths and Delusions. Biological Psychiatry 79(3): 243-250.

Lim M.M., Young L.J. 2006. Neuropeptidergic regulation of affiliative behavior and social bonding in animals. Hormones and Behavior 50(4): 506-517 doi: 10.1016/j.yhbeh.2006.06.028
Lucht M.J., Barnow S., Sonnenfeld C., Rosenberger A., Grabe H.J., Schroeder W., Völzke H., Freyberger H.J., Herrmann F.H., Kroemer H., Rosskopf D. 2009. Associations between the oxytocin receptor gene (OXTR) and affect, loneliness and intelligence in normal subjects. Progress in Neuro-psychopharmacology 33(5): 860-866. doi: 10.1016/j.pnpbp.2009.04.004

Ludwig M., Leng G. 2006. Dendritic peptide release and peptide-dependent behaviours. Nature Reviews Neuroscience 7(2): 126-136. doi: 10.1038/nrn1845

Macdonald K.S. 2012. Sex, receptors, and attachment: a review of individual factors influencing response to oxytocin. Frontiers in Neuroscience 6 . doi: 10.3389/fnins.2012.00194

McCullough, M. E., Churchland, P. S., Mendez, A. J. 2013. Problems with measuring peripheral oxytocin: Can the data on oxytocin andhuman behavior be trusted? Neuroscience and Biobehavioral Reviews 37: 14851492.

Miklósi Á., Kubinyi E., Topál J., Gácsi M., Virányi Z., Csányi V. 2003. A simple reason for a big difference: wolves do not look back at humans, but dogs do. Current Biology 13(9): 763-766.

Miklósi Á., Polgárdi R., Topál J., Csányi V. 1998. Use of experimenter-given cues in dogs. Animal Cognition 1: 113-121.

Miklósi, Á., Pongrácz, P., Lakatos, G., Topál, J., Csányi, V. 2005. A comparative study of the use of visual communicative signals in interactions between dogs (Canis familiaris) and humans and cats (Felis catus) and humans. Journal of comparative psychology 119(2): 179-186. doi: 10.1037/0735-7036.119.2.179

Miller S.C., Kennedy C., DeVole D., Hickey M., Nelson T., Kogan L. 2009. An examination of changes in oxytocin levels in men and women before and after interaction with a bonded dog. Anthrozoös 22(1): 31-42. 
Mitsui S., Yamamoto M., Nagasawa M., Mogi K., Kikusui T., Ohtani N., Ohta M. 2011. Urinary oxytocin as a noninvasive biomarker of positive emotion in dogs. Hormones and Behavior 60(3): 239-243. doi: 10.1016/j.yhbeh.2011.05.012

Montaldo H.H., Meza-Herrera C.A. 1998. Use of molecular markers and major genes in the genetic improvement of livestock. Electronic Journal of Biotechnology 1(2): 83-89. doi: 10.2225/vol1-issue2fulltext-4

Nagasawa M., Kikusui T., Onaka T., Ohta M. 2009. Dog's gaze at its owner increases owner's urinary oxytocin during social interaction. Hormones and Behavior 55(3): 434-441. doi: 10.1016/j.yhbeh.2008.12.002

Nagasawa M., Mitsui S., En S., Ohtani N., Ohta M., Sakuma Y., Onaka T., Mogi K., Kikusui T. 2015. Oxytocin-gaze positive loop and the coevolution of human-dog bonds. Science 348(6232): 333-336. doi: 10.1126/science.1261022

NCBI. 2012. OXTR oxytocin receptor [Canis lupus familiaris (dog)], annotation release 103. [ONLINE] Available at: http://www.ncbi.nlm.nih.gov/gene/484670.

Neumann, I. D., Maloumby, R., Beiderbeck, D. I., Lukas, M., Landgraf, R. 2013. Increased brain and plasma oxytocin after nasal and peripheral administration in rats and mice. Psychoneuroendocrinology 38: 1985-1993.

Odendaal J.S., Meintjes R.A. 2003. Neurophysiological correlates of affiliative behaviour between humans and dogs. Veterinary Journal 165(3): 296-301.

Oliva J.L., Rault J-L., Appleton B., Lill A. 2015. Oxytocin enhances the appropriate use of human social cues by the domestic dog (Canis familiaris) in an object choice task. Animal Cognition 18: 767-775. doi: 10.1007/s10071015-0843-7

Parker H.G., Shearin A.L., Ostrander E.A. 2010. Man's best friend becomes biology's best in the show: genome analysis in the domestic dog. Annual Review of Genetics 44: 309-336.
Rault J-L. 2016. Effects of positive and negative human contacts and intranasaloxytocin on cerebrospinal fluid oxytocin. Psychoneuroendocrinology, 69: 60-66.

Reid P. J. 2009. Adapting to the human world: dogs' responsiveness to our social cues. Behavioural processes, 80(3): 325-333. doi: 10.1016/j.beproc.2008.11.002

Riem M.M., Pieper S., Out D., Bakermans-Kranenburg M.J., van Ijzendoorn M.H. 2011. Oxytocin receptor gene and depressive symptoms associated with physiological reactivity to infant crying. Social Cognitive and Affective Neuroscience 6(3): 294-300. doi: 10.1093/scan/nsq035

Robinson I.C. 1983. Neurohypophysial peptides in cerebrospinal fluid. Progress in Brain Research 60: 129145. doi: 10.1016/S0079-6123(08)64381-2

Robinson I.C., Jones P.M. 1982. Oxytocin and neurophysin in plasma and CSF during suckling in the guinea-pig. Neuroendocrinology 34(1): 59-63.

Rodrigues S.M., Saslow L.R., Garcia N., John O.P., Keltner D. 2009. Oxytocin receptor genetic variation relates to empathy and stress reactivity in humans. Proceedings of the National Academy of Sciences USA 106(50): 21437-21441. doi: 10.1073/pnas.0909579106

Romero T., Nagasawa M., Mogi K., Hasegawa T., Kikusui T. 2014. Oxytocin promotes social bonding in dogs. Proceedings of the National Academy of Sciences 111(25): 9085-9090. doi: 10.1073/pnas.1322868111

Romero T., Nagasawa M., Mogi K., Hasegawa T., Kikusui T. 2015. Intranasal administration of oxytocin promotes social play in domestic dogs. Communicative and Integrative Biology 8(3): e1017157.

RSPCA. 2010. RSPCA Australia discussion paper: puppy farms (pp. 11)

Saphire-Bernstein S., Way B.M., Kim H.S., Sherman D.K., Taylor S.E. 2011. Oxytocin receptor gene (OXTR) is related to psychological resources. Proceedings of the National Academy of Sciences USA 108(37): 15118-15122. 
Schuelke M. 2000. An economic method for the fluorescent labeling of PCR fragments. Nature Biotechnology 18(2): 233-234. doi: 10.1038/72708

Scott, J.P. 1962. Critical periods in behavioral development. Science 138(3544): 949-958.

Soproni, K., Miklósi, A., Topál, J., Csányi, V. 2002. Dogs' (Canis familiaris) responsiveness to human pointing gestures. Journal of comparative psychology, 116(1): 27-34.

Striepens N., Kendrick K. M., Hanking V., Landgraf R., Wullner U., Maier W., Hurlemann R. 2013. Elevated cerebrospinal fluid and blood concentrations of oxytocin following its intranasal administration in humans. Scientific Reports 3: 3440. doi: 10.1038/srep03440

Sutter N.B., Ostrander E.A. 2004. Dog star rising: the canine genetic system. Nature Reviews Genetics 5(12):900-910 doi: 10.1038/nrg1492

Szeto A., McCabe P.M., Nation D.A., Tabak M.S., Rossetti M.A., McCullough M.E., Schneiderman N., Mendez A.J. 2011. Evaluation of enzyme immunoassay and radioimmunoassay methods for the measurement of plasma oxytocin. Psychosomatic Medicine 73(5): 393400. doi: 10.1097/PSY.0b013e31821df0c2

Tanaka K., Osako Y., Yuri K. 2010. Juvenile social experience regulates central neuropeptides relevant to emotional and social behaviors. Neuroscience 166(4): 1036-1042. doi: 10.1016/j.neuroscience.2010.01.029

Toonen R.J., Hughes S. 2001. Increased throughput for fragment analysis on an ABI PRISM 377 automated sequencer using a membrane comb and STRand software. Biotechniques 31: 1320-1324.

Tost H., Kolachana B., Hakimi S., Lemaitre H., Verchinski B.A., Mattay V.S., Weinberger D.R., MeyerLindenberg A. 2010. A common allele in the oxytocin receptor gene (OXTR) impacts prosocial temperament and human hypothalamic-limbic structure and function. Proceedings of the National Academy of Sciences USA 107(31): 13936-13941 doi: 10.1073/pnas.1003296107
Udell M.A., Giglio R.F., Wynne C.D. 2008a. Domestic dogs (Canis familiaris) use human gestures but not nonhuman tokens to find hidden food. Journal of Comparative Psychology 122(1): 84-93. doi: 10.1037/07357036.122.1.84

Untergasser A., Cutcutache I., Koressaar T., Ye J., Faircloth B.C., Remm M., Rozen S.G. 2012. Primer3-new capabilities and interfaces. Nucleic Acids Research, 40(15): e115.

Udell M.A.R., Dorey N.R., Wynne C.D.L. 2008b. Wolves outperform dogs in following human social cues. Animal Behaviour 76: 1767-1773.

Udell, M. A., Dorey, N. R., \& Wynne, C. D. 2010a. What did domestication do to dogs? A new account of dogs' sensitivity to human actions. Biological reviews of the Cambridge Philosophical Society, 85(2): 327-345. doi: 10.1111/j.1469-185X.2009.00104.x

Udell M.A.R., Dorey N.R., Wynne C.D.L. 2010b. The performance of stray dogs (Canis familiaris) living in a shelter on human-guided object-choice tasks. Animal Behaviour 79: 717-725.

Udell M. A. R., Wynne, C. D. L. 2010. Ontogeny and phylogeny: both are essential to human-sensitive behaviour in the genus Canis. Animal Behaviour 79: e9e14.

Veening J.G., de Jong T., Barendregt H.P. 2010. Oxytocin-messages via the cerebrospinal fluid: behavioral effects; a review. Physiology and Behavior 101(2): 193-210. doi: 10.1016/j.physbeh.2010.05.004

Virányi Z., Gácsi M., Kubinyi E., Topál J., Belényi B., Ujfalussy D., Miklósi Á. 2008. Comprehension of human pointing gestures in young human-reared wolves (Canis lupus) and dogs (Canis familiaris). Animal Cognition 11(3): 373-387. doi: 10.1007/s10071007-0127-y

Vorherr H., Bradbury M.W., Hoghoughi M., Kleeman C.R. 1968. Antidiuretic hormone in cerebrospinal fluid during endogenous and exogenous changes in its blood level. Endocrinology 83(2): 246-250. 
Wang G., Zhai W., Yang H., Fan R., Cao X., Zhong L., Wang L., Liu F., Wu H., Cheng L., Poyarkov A.D., Poyarkov N.A., Tang S., Zhao W., Gao Y., Lv X., Irwin D.M., Savolainen P., Wu C., Zhang Y. 2013. The genomics of selection in dogs and the parallel evolution between dogs and humans. Nature Communications 4. doi: $10.1038 /$ ncomms2814

Weaver B. 2013. Assumptions/Restrictions for Chisquare Tests on Contingency Tables. Retrieved March 27,2015
Wobber V., Hare B., Koler-Matznick J., Wrangham R., Tomasello M. 2009. Breed differences in domestic dogs' (Canis familiaris) comprehension of human communicative signals. Interaction Studies 10(2): 206224.

Wu S., Jia M., Ruan Y., Liu J., Guo Y., Shuang M., Gong X., Zhang Y., Yang X., Zhang D. 2005. Positive association of the oxytocin receptor gene (OXTR) with autism in the Chinese Han population. Biological Psychiatry 58(1): 74-77. doi: 10.1016/j.biopsych.2005.03.013 